OPEN ACCESS

Edited by:

Zuhua He,

Shanghai Institute for Biological

Sciences - Chinese Academy

of Sciences, China

Reviewed by:

Uener Kolukisaoglu,

University of Tübingen, Germany

Nabil I. Elsheery,

Tanta Univeristy, Egypt

Guodong Wang,

Institute of Genetics and

Developmental Biology, Chinese

Academy of Sciences, China

*Correspondence:

Muhammad Hamayun, Department of Botany, Abdul Wali Khan University Mardan, Mardan,

Pakistan

hamayun@awkum.edu.pk;

In-Jung Lee,

School of Applied Biosciences,

College of Agriculture and Life

Science, Kyungpook National

University, Daegu, South Korea

ijlee@knu.ac.kr

Specialty section: This article was submitted to Plant Physiology,

a section of the journal

Frontiers in Plant Science

Received: 29 January 2015

Accepted: 12 May 2015

Published: 01 June 2015

Citation

Hamayun M, Hussain A, Khan SA, Irshad $M$, Khan $A L$, Waqas $M$,

Shahzad R, lqbal $A$, Ullah $N$, Rehman G, Kim H-Y and Lee I-J

(2015) Kinetin modulates

physio-hormonal attributes and isoflavone contents of Soybean grown under salinity stress.

Front. Plant Sci. 6:377.

doi: 10.3389/fpls.2015.00377

\section{Kinetin modulates physio-hormonal attributes and isoflavone contents of Soybean grown under salinity stress}

\author{
Muhammad Hamayun ${ }^{*}$, Anwar Hussain', Sumera Afzal Khan², Muhammad Irshad', \\ Abdul Latif Khan ${ }^{3,4}$, Muhammad Waqas ${ }^{4}$, Raheem Shahzad ${ }^{4}$, Amjad lqbal $^{5}$, Nazif Ullah $^{6}$, \\ Gauhar Rehman ${ }^{7}$, Ho-Youn Kim ${ }^{8}$ and In-Jung Lee ${ }^{4 *}$ \\ ${ }^{1}$ Department of Botany, Abdul Wali Khan University Mardan, Mardan, Pakistan, ${ }^{2}$ Center of Biotechnology and Microbiology, \\ University of Peshawar, Peshawar, Pakistan, ${ }^{3}$ UoN Chair of Medicinal Plants and Marine Natural Products, University of \\ Nizwa, Nizwa, Oman, ${ }^{4}$ School of Applied Biosciences, College of Agriculture and Life Science, Kyungpook National \\ University, Daegu, South Korea, ${ }^{5}$ Department of Agriculture, Abdul Wali Khan University Mardan, Mardan, Pakistan, \\ ${ }^{6}$ Department of Biotechnology, Abdul Wali Khan University Mardan, Mardan, Pakistan, ' Department of Zoology, Abdul Wali \\ Khan University Mardan, Mardan, Pakistan, ${ }^{8}$ Department of Plant Sciences, University of California Davis, Davis, CA, USA
}

Crop productivity continues to decline due to a wide array of biotic and abiotic stresses. Salinity is one of the worst abiotic stresses, as it causes huge losses to crop yield each year. Kinetin $(\mathrm{Kn})$ has been reported as plant growth regulator since long, but its role in improving plant growth and food quality under saline conditions through mediating phytohormonal cross-talk is poorly studied. Current study was designed to evaluate the impact of exogenously applied Kn on growth, isoflovones and endogenous phytohormones of soybean grown under $\mathrm{NaCl}$ induced salt stress. Soybean plants were grown in perlite (semi hydroponic), and under controlled green-house conditions. Elevated levels of exogenous Kn significantly mitigated the adverse effect of $\mathrm{NaCl}$ and rescued plant growth attributes, i.e., plant height, fresh and dry biomass of soybean plants grown in all treatments. Higher diadzen, glycitin, and genistin contents were observed in plants treated with elevated $\mathrm{Kn}$ in the presence or absence of $\mathrm{NaCl}$ induce salt stress. The gibberellins (GAs) biosynthesis pathway was up-regulated by $\mathrm{Kn}$ as the bioactive $\mathrm{GA}_{1}$ and $\mathrm{GA}_{4}$ contents were significantly higher in $\mathrm{Kn}$ treated plants, as compared to control, while GAs level reduced in $\mathrm{NaCl}$ treated plants. Contrary to GAs, the abscisic acid contents declined with $\mathrm{Kn}$ but promoted in $\mathrm{NaCl}$ stressed soybean plants. The endogenous jasmonic acid and salicylic acid contents of soybean enhanced with elevated $\mathrm{Kn}$ application, but they showed an antagonistic response under salt stress. Current study supports the active role of $\mathrm{Kn}$ to ameliorate the adverse effects of salt stress on the growth and food quality of soybean. The favorable role of Kn toward soybean growth under salt stress may be attributed to its potential to modulate crosstalk between the various phytohormones involved in soybean growth and its resistance to salinity stress.

Keywords: kinetin, soybean, salt stress, gibberellins, abscisic acid, jasmonic acid, salicylic acid 


\section{Introduction}

The arable land continues to decline globally, as it is rendered unfavorable for cultivation due to a wide array of environmental constraints. Salinity is a major agricultural problem that is responsible for low yield on approximately 33\% (40 million hectares) the irrigated land on earth (Norlyn and Epstein, 1984). If lifted untreated, the problem will become more severe by affecting approximately $50 \%$ of the arable land by 2050 (Hussain et al., 2008). Saline soils are characterized by high levels of sodium $\left(\mathrm{Na}^{+}\right)$and chloride $\left(\mathrm{Cl}^{-}\right)$ions that interfere with the normal growth and yield of the plants cultivated in such soils. Induced ionic and osmotic imbalance is the common mechanism through which salt stress affects plant metabolism ultimately resulting abnormal growth. Under saline conditions, plant cell accumulate compatible osmolytes and consequently uptake additional water from surrounding, thereby buffering the immediate effect of salts (Bartels and Sunkar, 2005; Misra and Gupta, 2005; Verbruggen and Hermans, 2008). However, growth of leguminous plants particularly soybean is severely affected by salts (Pathan et al., 2007), where slow growth is associated with restricted root water uptake and abnormal cell physiology (Apse et al., 1999; Zhu, 2002).

Soybean is a vital source of human nutrition across the world. Soybean is mostly grown for oil production, while a smaller portion is directly used by humans. Soybean and its products (chungkookjang, doenjang, douchi, ganjang, miso, natto, and tofu) constitute an important part of daily diet in countries like China, Korea, and Japan. There is an increase in soybean consumption worldwide, due to nutritional value attributed to the presence of healthy isoflavone. Isoflavone is important in human health-care, such as cardiovascular diseases, menopausal symptoms, bone resorption, and breast, prostate, and colon cancers (Messina, 2000; Allred et al., 2004). Daidzein and genistein are two most important isoflavone isomers, and are regarded as phytoestrogens due to their favorable role in human health-care (Omoni and Aluko, 2005). The isoflavones are chemically categorized in to four subgroups, i.e., aglycones, glycosides, malonyl glycoside, and acetyl glycosides (Ososki and Kennelly, 2003).

Plants integrate environmental signals (such as salinity) and phytohormonal signals [such as abscisic acid (ABA), gibberellins (GAs), jasmonic acid (JA), and salicylic acid (SA)] during growth regulation. The plant hormones are present in very minute quantities, yet they are crucial for plant growth and development. For instance, GAs are vital for seed germination, stem elongation, leaf expansion, and flowering (Magome et al., 2004), while JA influences seed germination, root growth, senescence, fertility, and fruit ripening (Creelman and Mulpuri, 2002; Wasternack and Hause, 2002). Additionally, JA is an essential component of plant immunity in insect-driven wounding, pathogens, and abiotic stresses such as low temperature, salinity, and drought (Wasternack and Parthier, 1997). Another phytohormone, SA mediates plant responses to a wide range of stresses, enabling plants to survive in conditions of biotic and abiotic stresses including salt stress (Keskin et al., 2010). Additionally, ABA regulates several physiological processes in plants including photosynthesis, growth, nitrate metabolism, heat production, ethylene production and flowering (Hayat et al., 2010).

Different strategies have been working to promote plant growth and productivity under saline conditions. Improving plant tolerance to salinity through conventional plant breeding techniques are laborious, time consuming, and depend upon the existing genetic variability. In addition, many attempts have been made to overcome salinity stress, including proper management and exogenous application of plant growth regulators (Javid et al., 2011). Kinetin (Kn), a synthetic cytokinin (CK) has been previously reported for reprogramming higher plant performance under normal and saline conditions. Beside a long history of Kn applications for the alleviation of salt stress in plants, little has been known about its role in the modulation of physio-hormonal attributes and enhancement of nutritional quality of plants under salinity. It has been reported that application of $\mathrm{Kn}$ modulates phenolic metabolism of Vigna sinensis and Zea mays grown under salt stress (Nemat Alla et al., 2002). Salt stressed phenotype of salt sensitive plants is normally characterized by low level of endogenous CKs which indicates that CKs levels could be a limiting factor under stress conditions. This may be a possible explanation of the growth improvement in salt stressed chickpea by the exogenous application of Kn. However, exposure of facultative halophyte Mesembryanthemum crystallinum to salt stress caused no change in the endogenous levels of zeatin-type CKs (Thomas and Bohnert, 1993). It has been suggested that Kn scavenges free radicals or it may be involved in antioxidative mechanism related to the protection of purine breakdown (Chakrabarti and Mukherji, 2003). Using mutant Arabidopsis, it has been demonstrated that CKs receptors act as negative regulators in ABA signaling as well as in osmotic stress responses (Tran et al., 2007). However, very little is known on interaction of kinetine with phytohormones other than ABA under saline conditions. In current study, we investigate the effect of $\mathrm{Kn}$ and $\mathrm{NaCl}$ on the growth attributes and food quality of hydroponically grown soybean cv. Daewonkong. Furthermore, a hormonal cross-talk resulting from $\mathrm{Kn}$ and $\mathrm{NaCl}$ application is also studied.

\section{Materials and Methods}

\section{Plant Material and Growth Conditions}

Surface sterilized seeds of soybean cultivar Daewonkong were sown in perlite containing pots $(15 \mathrm{~L})$ and kept under greenhouse conditions. Sterilization was done with $5 \%$ solution of sodium hypochlorite $(\mathrm{NaOCl})$ for $15 \mathrm{~min}$ followed by thorough rinsing with distilled $\mathrm{H}_{2} \mathrm{O}$. Modified hoagland solution containing

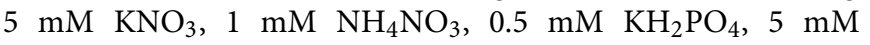
$\mathrm{Ca}\left(\mathrm{NO}_{3}\right)_{2} 4 \mathrm{H}_{2} \mathrm{O}, 1.5 \mathrm{mM}$ Fe-EDTA, $2 \mathrm{mM} \mathrm{MgSO}_{4} .7 \mathrm{H}_{2} \mathrm{O}$, and other micro-nutrient in their original concentrations were used as fertilizer (Yoon et al., 2009). Kn was applied in the elevated conc. of $0.5,1$, and $5 \mu \mathrm{M}$, while a single conc. of $\mathrm{NaCl}(100 \mathrm{mM})$ was applied to soybean after 17 days of sowing (17 DAS). Each pot contained three plants, and received a single dose of $\mathrm{Kn}$ $(50 \mathrm{ml})$ and $\mathrm{NaCl}(400 \mathrm{ml})$ at $17 \mathrm{DAS}$. Soybean plants were harvested after 2 weeks of $\mathrm{Kn}$ and $\mathrm{NaCl}$ application. However, 
for phytohormonal analysis, one-third of plants per treatment were harvested after $24 \mathrm{~h}$ of $\mathrm{Kn}$ and $\mathrm{NaCl}$ treatment, immediately frozen in liquid nitrogen, and later stored in refrigerator (Sanyoultra low, Japan) at $-80^{\circ} \mathrm{C}$. The experiment was designed as randomized complete block design (RCBD), consisting of eight treatments and 15 replicates per treatment.

\section{Growth Attributes Analysis}

Soybean growth attributes, viz., plant length, shoot and root fresh and dry weights were measured at the harvest time, while chlorophyll content of fully expanded leaves was analyzed with the help of chlorophyll meter (Minolta Co., Ltd, Japan) just before the harvest (Hamayun et al., 2010). For soybean growth analysis, 20 plants per treatment were randomly selected. The dry biomass was measured after drying the plants at $70^{\circ} \mathrm{C}$ for $48 \mathrm{~h}$ in an oven (Bohm, 1979).

\section{Isoflavones Analysis}

Isoflavones content of soybean leaves were measured by following the already established standard protocols (Rostagno et al., 2003; Phommalth et al., 2008). Soybean leaves were crushed to powder form, and $0.2 \mathrm{~g}$ of this powder was added to $10 \mathrm{ml}$ of $80 \% \mathrm{EtOH}$ and kept for $1 \mathrm{~h}$ in Ultrasonic bath (Kodo Co., Korea) set at $50^{\circ} \mathrm{C}$. The samples were then kept in a shaking incubator (150 rpm) at $50^{\circ} \mathrm{C}$ for $15 \mathrm{~h}$ and then filtered through $0.45 \mu \mathrm{m}$ syringe filter. The filtered samples $(10 \mu \mathrm{l})$ were injected using gradient solutions, viz., acetonitrile and $0.1 \%$ of acetic acid in water by using TOTALCHROM V6.2.0.0.1 system with LC instrument control (PerkinElmer Series 200, USA), and a COL-CHOICE $\mathrm{C}_{18}$ column $4.6 \mathrm{~mm} \times 150 \mathrm{~mm}(5 \mu \mathrm{m})$ packed. Sample elution was done at a flow rate of $1.0 \mathrm{ml} / \mathrm{min}$ and flavones in the sample were determined by UV-absorption (Series 200 UV/Vis Detector) at $260 \mathrm{~nm}$. Identification of the isoflavones were based on comparisons with retention times of internal standards, including daidzein, genistein, and genistin (Sigma Chemical Co, USA), as well as glycitin, daidzin, 6'-0-actlygnistin, 6'-0-malonygenistin, and $6^{\prime}-0$-actyldaidzin (LC Laboratory, USA).

\section{Analysis of Endogenous Phytohormones Gibberellins Analysis}

Soybean shoot samples were lyophilized and then crushed to powder form. The powdered sample $(0.5 \mathrm{~g})$ was used for extraction and quantification of bioactive $\mathrm{GA}_{1}$ and $\mathrm{GA}_{4}$, following an established protocol (Lee et al., 1998). The GC (Hewlett-Packard 6890, 5973N mass selective detector) was equipped with HA-1 capillary column $(30 \mathrm{~m} \times 0.25 \mathrm{~mm}$ i.d. $0.25 \mu \mathrm{m}$ film thickness), and oven temperature was programmed at $60^{\circ} \mathrm{C}$ for $1 \mathrm{~min}$, then a rise of $15^{\circ} \mathrm{C} \mathrm{m^{-1 }}$ to $200^{\circ} \mathrm{C}$, followed by rise of $5^{\circ} \mathrm{C} \min ^{-1}$ to $285^{\circ} \mathrm{C}$. Helium carrier gas was kept at a head pressure of $30 \mathrm{kPa}$. The GC was directly interfaced to a mass selective detector with an interface and source temperature of $280^{\circ} \mathrm{C}$, an ionizing voltage of $70 \mathrm{eV}$, and a dwell time of $100 \mathrm{~ms}$. Full scan mode (the first trial) and three major ions of the supplemented $\left({ }^{2} \mathrm{H}_{2}\right)$ GAs internal standards (the second trial), and the endogenous GAs were monitored simultaneously (standard GAs were purchased from Prof. Lewis N. Mander, Australian National University, Canberra, ACT, Australia). The endogenous $\mathrm{GA}_{1}$ and $\mathrm{GA}_{4}$ contents were calculated from the peak area ratios of 506/508 and 284/286, respectively. The data was calculated in nano-grams per gram dry weight and the analysis was repeated three times.

\section{Salicylic Acid (SA) Analysis}

The endogenous free SA contents of soybean shoots were extracted and quantified as described (Enyedi et al., 1992; Seskar et al., 1998). Freeze-dried leaves $(0.1 \mathrm{~g})$ were ground to fine powder under liquid nitrogen and subjected to extraction sequentially done with 90 and $100 \%$ methanol $(\mathrm{MeOH})$ by centrifuging at $10,000 \times g$. The pooled $\mathrm{MeOH}$ fractions dried under vacuum and the pellet was resuspended in $2.5 \mathrm{ml}$ of $5 \%$ trichloroacetic acid. For further fractionation, ethyl acetate (EtOAc)/cyclopentane/isopropanol (49.5:49.5:1, v/v) was added and the free SA containing top organic layer was dried under nitrogen gas in a $4 \mathrm{ml}$ vial. It was re-suspended in $1 \mathrm{~mL}$ of $70 \% \mathrm{MeOH}$. Determination of SA was performed on HPLC (Shimadzu, Japan) equipped with fluorescence detector (Shimadzu RF-10AXL, excitation and emission detected at 305 and $365 \mathrm{~nm}$, respectively) and C18 reverse-phase column (HP hypersil ODS; particle size, $5 \mu \mathrm{m}$; pore size, 120 - $\AA$ water). Sample was eluted at a flow rate of $1.0 \mathrm{ml} / \mathrm{min}$.

\section{Abscisic Acid (ABA) Analysis}

Leave were ground to fine powder in liquid nitrogen for extraction of ABA as described earlier (Yoon et al., 2009). To the powder, $30 \mathrm{ml}$ of extraction solution containing 95\% isopropanol, $5 \%$ glacial acetic acid, and $20 \mathrm{ng}$ of $[( \pm)-3,5,5,7,7,7-\mathrm{d} 6]-\mathrm{ABA}$ were added. After proper mixing and filtration the filtrate was dried by a rotary evaporator. The residue was taken in $4 \mathrm{ml}$ of $1 \mathrm{~N}$ sodium hydroxide solution and washed three times with $3 \mathrm{ml}$ of methylene chloride for the removal of lipophilic materials. After setting $\mathrm{pH}$ of the aqueous phase to 3.5 with $6 \mathrm{~N}$ hydrochloric acid, it was partitioned with EtOAc three times. Pooled EtOAc extracts were then evaporated and the dried residue was dissolved in phosphate buffer $(\mathrm{pH} \mathrm{8.0)}$. The sample was then passed through a polyvinylpolypyrrolidone (PVPP) column. Again, $\mathrm{pH}$ of the phosphate was adjusted to 3.5 with $6 \mathrm{~N} \mathrm{HCl}$ and partitioned three times into EtOAc. After evaporating the pooled fractions to dryness, the residue was dissolved in dichloromethane $\left(\mathrm{CH}_{2} \mathrm{Cl}_{2}\right)$ and passed through a silica cartridge (Sep-Pak; Water Associates, Milford, MA, USA) pre-washed with $10 \mathrm{ml}$ of diethyl ether: $\mathrm{MeOH}(3: 2, \mathrm{v} / \mathrm{v})$ and $10 \mathrm{ml}$ of dichloromethane. ABA was eluted from the cartridge with $10 \mathrm{ml}$ of diethyl ether $\left(\mathrm{CH}_{3}-\mathrm{CH}_{2}\right)_{2} \mathrm{O}: \mathrm{MeOH}(3: 2, \mathrm{v} / \mathrm{v})$. The extracts were dried and methylated by adding diazomethane for GC/MS-SIM (6890 N network GC system, and the 5973 network mass-selective detector; Agilent Technologies, Palo Alto, CA, USA) analysis. For quantification, the Lab-Base (ThermoQuset, Manchester, UK) data system software was used to monitor responses to ions with an m/e of 162 and 190 for Me-ABA and 166 and 194 for Me- $\left[{ }^{2} \mathrm{H} 6\right]-\mathrm{ABA}$.

\section{Jasmonic Acid (JA) Analysis}

The endogenous JA contents of soybean shoots were determined by following a modified version of the protocol of McCloud and 
Baldwin (1997). Fine powder made by grinding the lyophilized samples $(0.1 \mathrm{gm})$ was suspended in a solution of acetone and $50 \mathrm{mM}$ citric acid (70:30, v/v), containing $\left[9,10-{ }^{2} \mathrm{H}_{2}\right]-9,10-$ dihydro-JA (20 ng) as an internal standard. The suspension was kept overnight under room temperature for slow evaporation necessary for avoiding the loss of fatty acids of volatile nature. On the next day, the resultant aqueous solutions were filtered and the filtrate was extracted three times with $10 \mathrm{ml}$ of diethyl ether. Solid phase extraction cartridge (500 $\mathrm{mg}$ of sorbent, aminopropyl) was loaded with the pooled extracts and washed with $7 \mathrm{ml}$ of trichloromethane and 2-propanol $(2: 1, \mathrm{v} / \mathrm{v})$. Elution of the bound JA and the relevant standard was carried out with a mixture of $10 \mathrm{ml}$ of diethyl ether and acetic acid $(98: 2, \mathrm{v} / \mathrm{v})$. The residue obtained after evaporation of solvents was esterified with excess diazomethane and its volume was brought to $50 \mu \mathrm{l}$ with dichloromethane. Quantification of JA was done by GC/MS (6890N network GC system, and 5973 network mass selective detector; Agilent Technologies, Palo Alto, CA, USA). To enhance the sensitivity of the method, spectra were recorded in the selected ion mode, i.e., in case of JA determination, monitored the fragment ion at $m / z=83$ amu corresponding to the base peaks of JA and $\left[9,10-{ }^{2} \mathrm{H}_{2}\right]-9,10$-dihydro-JA (Koch et al., 1999). Amount of JA was calculated and represented as nano-grams per gram dry weight. Experiment was repeated three times.

\section{Statistical Analysis}

Sigma Plot software (2004) was used to calculate SD and SE using of the data. The mean values were compared using Duncan's multiple range tests at $P<0.05$ (ANOVA SAS release 9.1; SAS, Cary, NC, USA).

\section{Results}

\section{Kinetin Promotes Plant Growth and Mitigates Salinity Stress}

Soybean growth was significantly promoted by elevated Kn levels and rescued plant growth under $\mathrm{NaCl}$ salt stress. Maximum shoot length $(90.92 \mathrm{~cm})$ was recorded for plants that received combined dose of $\mathrm{Kn}(0.5 \mu \mathrm{M})$ and $\mathrm{NaCl}$, while highest shoot fresh biomass $(7.57 \mathrm{gm})$, shoot dry biomass (1.66 gm), root fresh biomass (10.53 gm), and root dry biomass (1.13 gm) were observed in Kn $(1 \mu \mathrm{M})$ treated plants (Figure 1). The chlorophyll contents were not much affected by $\mathrm{Kn}$ and $\mathrm{NaCl}$ application. Sole application of $\mathrm{NaCl}$ greatly obstructed growth attributes of soybean. The chlorophyll contents of soybean leaves significantly declined under stress conditions as compared to control. Current findings suggest that $\mathrm{Kn}$ application enhanced soybean growth by alleviating the negative effect of $\mathrm{NaCl}$ (Figure 1).

\section{Kinetin Improved Soybean Isoflavone Contents}

Isoflavones analysis showed that both $\mathrm{Kn}$ and salt stress significantly affected their levels in soybean leaves (Figure 2). Salt stress significantly decreased the total isoflavones, while Kn effectively improved the quantities of isoflavones, and mitigated the negative impact of $\mathrm{NaCl}$ induced salt stress on isoflavone biosynthesis. Maximum isoflavone content $(610.9 \mu \mathrm{g} / \mathrm{g})$ was found in $\mathrm{Kn}(1 \mu \mathrm{M})$ treated plant, while least $(159.8 \mu \mathrm{g} / \mathrm{g})$ in $\mathrm{NaCl}$ treated plants, as compared to $354.3 \mu \mathrm{g} / \mathrm{g}$ in control (Figure 2). Similarly, maximum quantities of the highly valued phytoestrogens (daidzein and genistein) were observed in $\mathrm{Kn}$ $(1 \mu \mathrm{M})$ treated plants (Figures 3 and 4). Current study reports the favorable role of $\mathrm{Kn}$ on the isoflavones content of soybean, and suggest that $\mathrm{Kn}$ counteracted the negative effect of the $\mathrm{NaCl}$ induced salt stress on isoflavones biosynthesis. It was also observed that daidzein was more abundant than genistein in the soybean (Figures 3 and 4 ).

\section{Kinetin Stimulates Endogenous Gibberellins Biosynthesis in Soybean}

Kinetin application significantly enhanced bioactive $\mathrm{GA}_{1}$ and $\mathrm{GA}_{4}$ contents of soybean, while salt stress markedly reduced biosynthesis of bioactive GAs. The bioactive GAs (GA 1 and $\left.\mathrm{GA}_{4}\right)$ levels increased with elevated $\mathrm{Kn}$ application as maximum $\mathrm{GA}_{1}$ $(5.86 \mathrm{ng} / \mathrm{g})$ and $\mathrm{GA}_{4}(11.34 \mathrm{ng} / \mathrm{g})$ contents were found in plants that received $5 \mu \mathrm{M} \mathrm{Kn}$ (see Figure 5). On the other-hand $\mathrm{NaCl}$ treated plants contained significantly reduced $\mathrm{GA}_{1}(0.73 \mathrm{ng} / \mathrm{g})$ and $\mathrm{GA}_{4}(1.64 \mathrm{ng} / \mathrm{g})$ contents, while plants treated with both $\mathrm{Kn}$ and $\mathrm{NaCl}$ showed considerable recovery as compared to sole $\mathrm{NaCl}$ treatments (Figure 5). Current finding clearly suggests that $\mathrm{Kn}$ stimulates GA biosynthesis in soybean under saline conditions.

\section{Kinetin Stimulates Free Salicylic Acid Biosynthesis in Soybean}

The endogenous free SA contents of soybean significantly increased with the addition of elevated $\mathrm{Kn}$ but markedly decreased in sole $\mathrm{NaCl}$ treated plants. However, an addition of $\mathrm{Kn}$ to $\mathrm{NaCl}$ treatments showed a significant SA recovery, as maximum free SA contents $(4.73 \mathrm{ng} / \mathrm{g})$ was documented in plants that received $5 \mu \mathrm{M} \mathrm{Kn}$ and $100 \mathrm{mM} \mathrm{NaCl}$ (Figure 6). Current finding suggests that Kn stimulates free SA biosynthesis in soybean, while an addition of $\mathrm{Kn}$ to salt stress plants greatly mitigated the down-regulatory effect of $\mathrm{NaCl}$ on these plants (Figure 6).

\section{Kinetin Down-Regulate ABA Biosynthesis in Soybean}

Abscisic acid analysis showed that endogenous free ABA contents of soybean considerably decreased in plants treated with elevated $\mathrm{Kn}$, as compared to control. Contrary to $\mathrm{Kn}$, the $\mathrm{NaCl}$ treated plants recorded maximum ABA contents (1480.6 ng/g), while the quantity of ABA was significantly higher in treatments that received both of $\mathrm{Kn}$ and salinity stress as compared to sole application of Kn (Figure 7). Current study suggests that $\mathrm{NaCl}$ triggers higher ABA biosyntheses in soybean, while addition of Kn hinders such process.

\section{Kinetin up-Regulates Jasmonic Acid Contents but Show Antagonism Under Salt Stress}

Sole application of elevated $\mathrm{Kn}$ considerably promoted endogenous JA contents of soybean; although $\mathrm{Kn}$ hindered JA biosynthesis in the presence of $\mathrm{NaCl}$ induced salt stress (Figure 8). Contrary to $\mathrm{Kn}$, addition of $\mathrm{NaCl}$ 


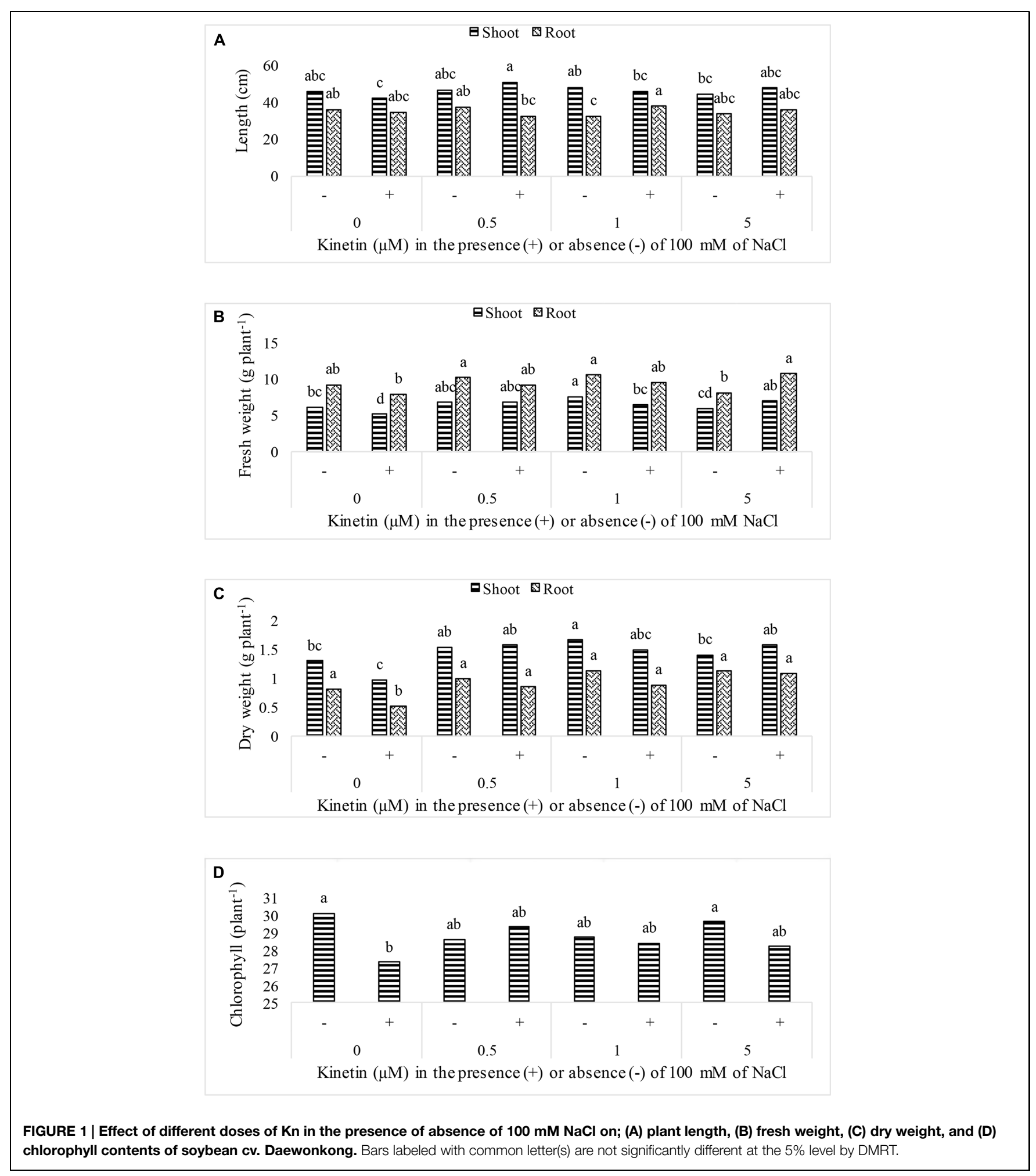

significantly up-regulated JA contents (153.47 $\mathrm{ng} / \mathrm{g})$ as compared to control $(79.07 \mathrm{ng} / \mathrm{g})$. Current study demonstrates that $\mathrm{Kn}$ antagonistically affect JA biosynthesis, as $\mathrm{Kn}$ hinders JA biosynthesis in salt stressed soybean plants.

\section{Discussion}

Soil affected with salinity is a major limiting factor to feed human population because it interferes with crop yield and our current research findings confirm it, as growth variables of soybean 


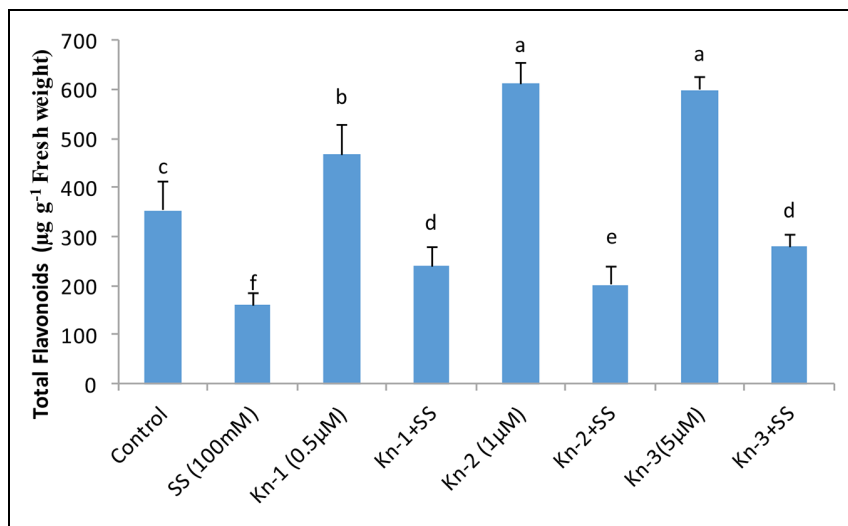

FIGURE 2 | Effect of $\mathrm{Kn}$ and salt stress on the concentrations of total flavonoids in soybean cv. Daewonkong. Bars in the graph represent means of three replicated with \pm SEM. Bars labeled with same letter are not significantly different at $P>0.05$ by Duncan Multiple Range Test (DMRT). drastically decreased in all treatments exposed to $\mathrm{NaCl}$ induced salt stress. There are multiple reasons for a declined crop growth under saline conditions. High amount of $\mathrm{Na}^{+}$in soybean cell reduce its growth by making osmotic potential more negative, thereby reducing the uptake of water and minerals like $\mathrm{K}^{+}$and $\mathrm{Ca}^{2+}$. Maintaining a low $\mathrm{Na}^{+} / \mathrm{K}^{+}$ratio in cytosol is essential for normal cell because $\mathrm{K}^{+}$activates more than 50 cytosolic enzymes which do not function normally under high $\mathrm{Na}^{+} / \mathrm{K}^{+}$ratios (Zhu et al., 1998; Munns et al., 2006). Being physico-chemically similar, these monovalent cations compete each other for uptake by plant root. Thus, under saline conditions, greater uptake of $\mathrm{Na}^{+}$results in high $\mathrm{Na}^{+} / \mathrm{K}^{+}$ratios in the cytosol, which exert metabolic toxicity as they compete for the binding sites of several enzymes (Tester and Davenport, 2003). When chloroplast of soybean accumulates excessive amount of $\mathrm{Na}^{+}$, light driven electron flow is often significantly reduced, accompanied by inhibition of PS-II activity and reduced growth rate (Kirst, 1990; Kao et al., 2003). Low chlorophyll phenotype of soybean under elevated $\mathrm{Na}^{+}$stress has been associated with enhanced ethylene production which is

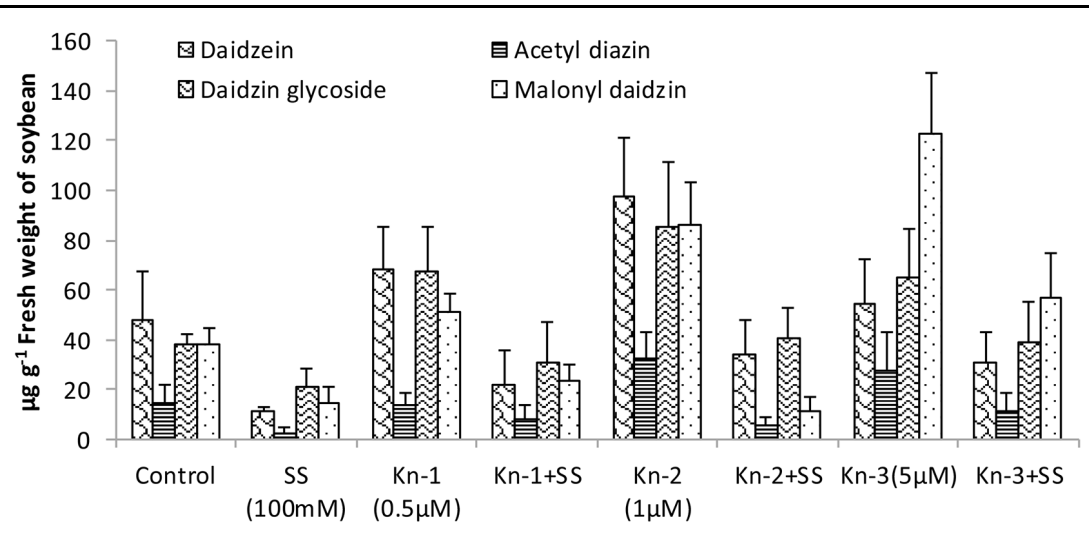

FIGURE 3 | Effect of $\mathrm{Kn}$ and salt stress on the concentrations of aglycones, acetyl glycosides, glycosides and malonyl glycosides of daizein in soybean cv. Daewonkong. Bars in the graph represent means of three replicated with \pm SEM.

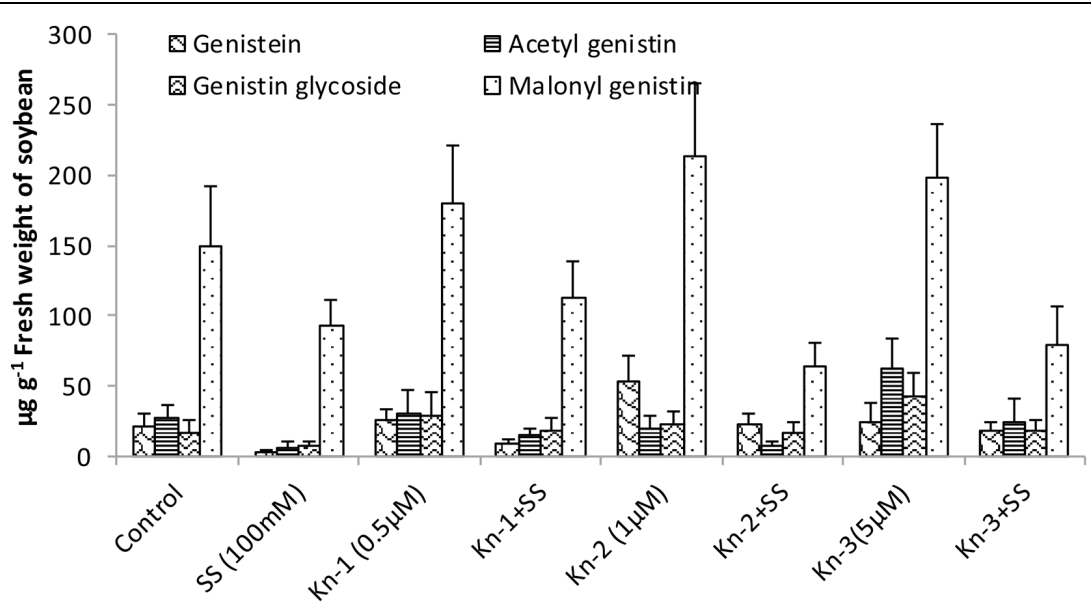

FIGURE 4 | Effect of $\mathrm{Kn}$ and salt stress on the concentrations of aglycones, acetyl glycosides, glycosides and malonyl glycosides of genistin in soybean cv. Daewonkong. Bars in the graph represent means of three replicated with $\pm S E M$. 


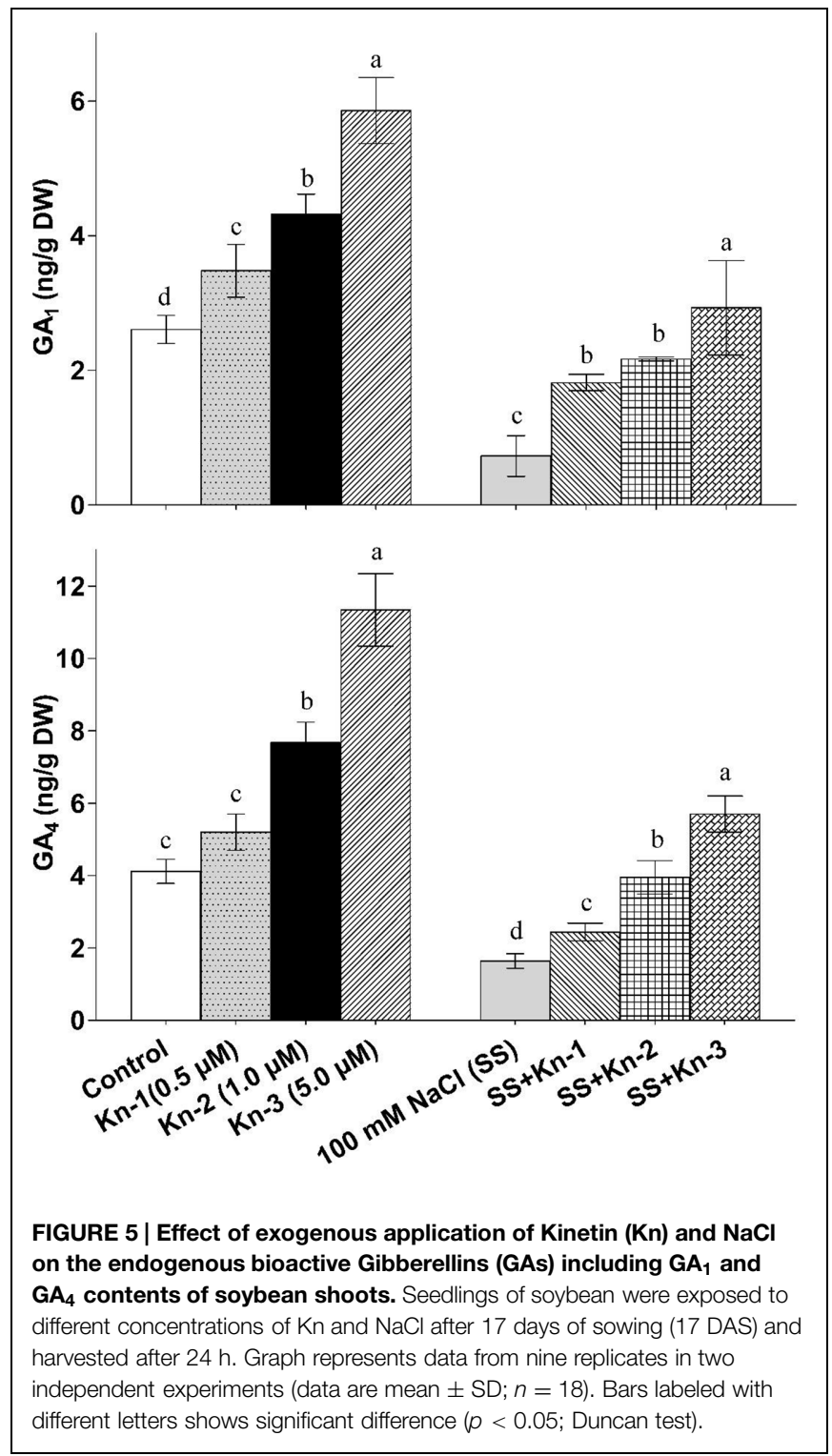

followed by inhibition of chlorophyll biosynthesis (Khan, 2003). The situation is further complicated by increased activity of chlorophylase in plants growing under stress (Singh and Jain, 1982). Hence, low chlorophyll content could be the result of less production and enhanced degradation of this pigment under salt stress. Contrary to the effect of salt stress on soybean, Kn significantly ameliorated the negative impact of salt stress on growth characteristics of soybean. The chlorophyll contents per unit area of soybean was little lower in $\mathrm{Kn}$ treated plants as compared to control, but as the leaf size was bigger in these plants, so the total chlorophyll contents could be much higher (Hamayun et al., 2010). Our current findings confirm earlier reports on the favorable role of $\mathrm{Kn}$ in growth and biomass of strawberry, maize, and apple (Gunes et al., 2007; Sharma and Singh, 2009).

Quality of the food can be improved by enhancing the quantities of beneficial compounds present in our food.
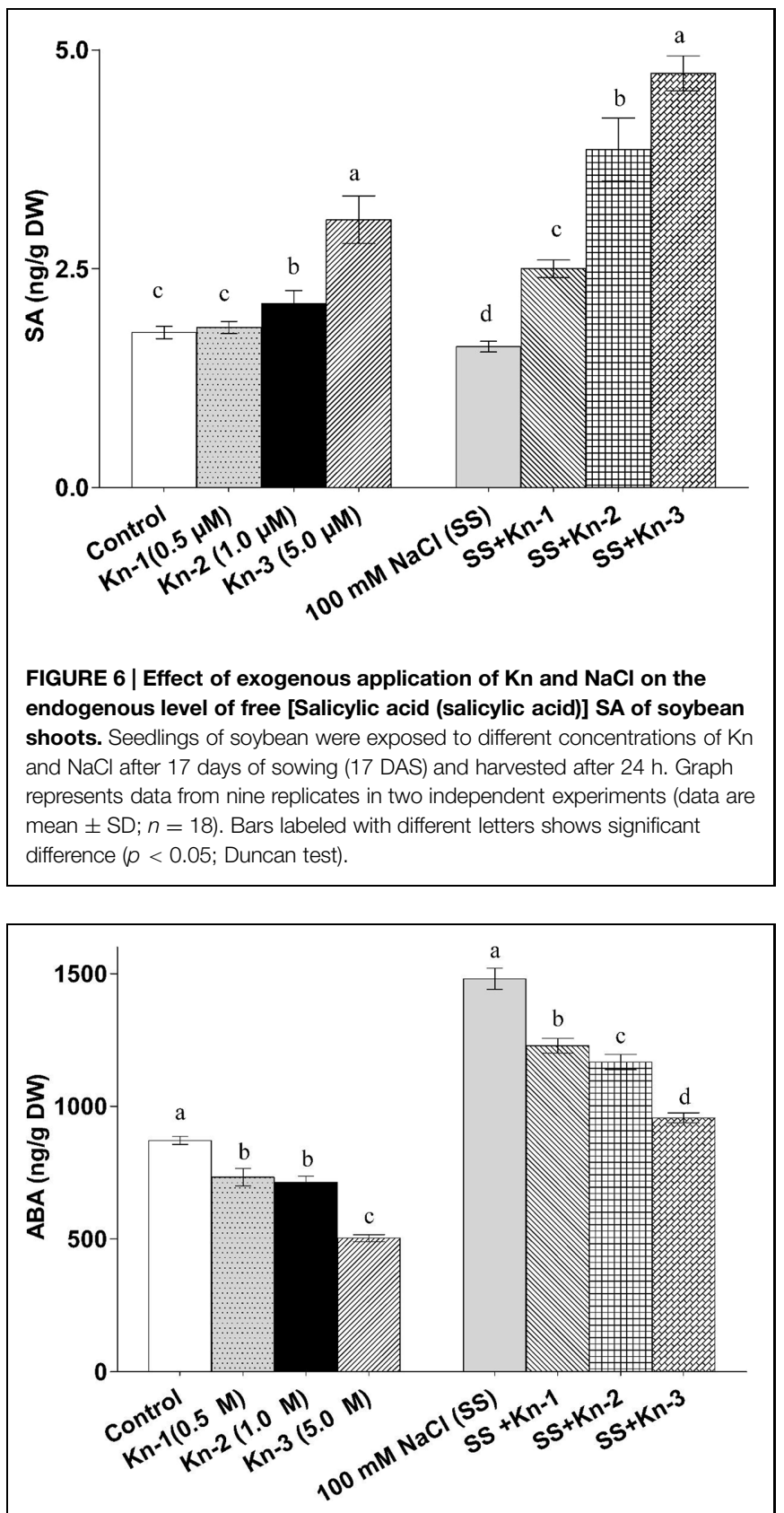

FIGURE 7 | Effect of exogenous application of $\mathrm{Kn}$ and $\mathrm{NaCl}$ on the endogenous level of Abscisic acid (ABA) of soybean shoots. Seedlings of soybean were exposed to different concentrations of $\mathrm{Kn}$ and $\mathrm{NaCl}$ after 17 days of sowing (17 DAS) and harvested after $24 \mathrm{~h}$. Graph represents data from nine replicates in two independent experiments (data are mean \pm SD; $n=18$ ). Bars labeled with different letters shows significant difference ( $p<0.05$; Duncan test).

Isoflavones are highly valued for human health, and soybean cultivars with higher isoflavones content have been developed over the past years (Phommalth et al., 2008). Our findings showed that addition of Kn significantly enhanced isoflovenes content of soybean and mitigated the negative effect of $\mathrm{NaCl}$ induced salt stress on their biosynthesis. Previous researches confirmed that 


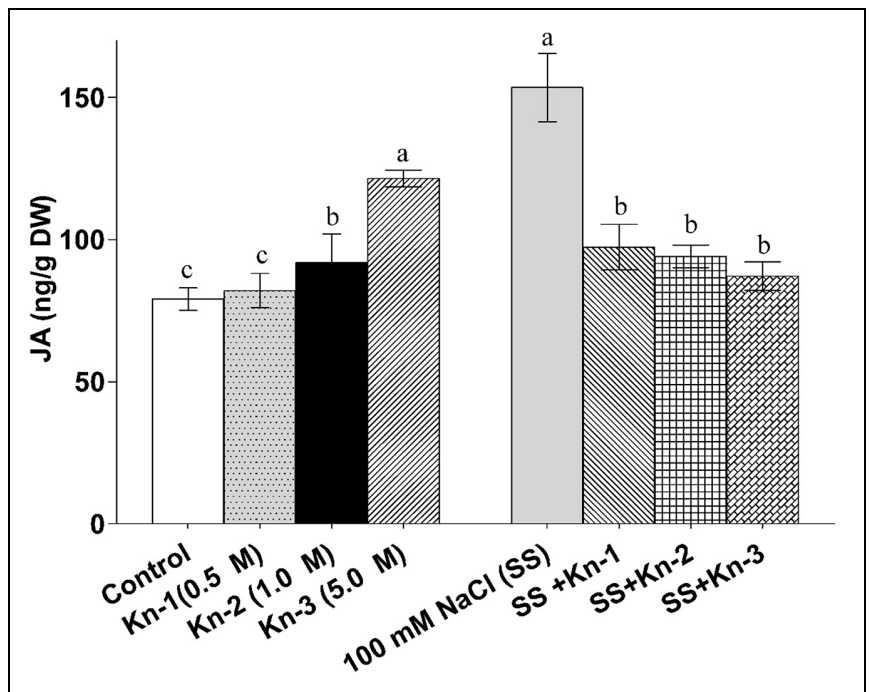

FIGURE 8 | Effect of exogenous application of $\mathrm{Kn}$ and $\mathrm{NaCl}$ on the endogenous level of Jasmonic acid (JA) of soybean shoots. Seedlings of soybean were exposed to different concentrations of $\mathrm{Kn}$ and $\mathrm{NaCl}$ after 17 days of sowing (17 DAS) and harvested after $24 \mathrm{~h}$. Graph represents data from nine replicates in two independent experiments (data are mean $\pm S D$; $n=18)$. Bars labeled with different letters shows significant difference ( $p<0.05$; Duncan test).

cytokinins have been shown to cause an increase in anthocyanin accumulation in tissue culture and in parts of intact plants (Deikman and Hammer, 1995). Positive correlation has been reported in anthocyanin biosynthesis and the co-ordinated appearance of relevant enzymes including chalcone flavanone isomerase (CHI), flavanone-3-hydroxylase, phenylalanine ammonia-lyase (PAL), 3-O-flavonoid-glucosyltransferase and chalcone synthase (CHS; Dangelmayr et al., 1983; Gerats et al., 1983). All of these enzymes control the biosynthesis of isoflavones (Barz and Welle, 1992). As both anthocyanin and isoflavones are synthesized from phenylalanine through a common pathway sharing many enzymes including PAL, CHI, and CHS (Winkel-Shirley, 2001) advocating the enhanced accumulation of isoflavone in CKs treated plants. As an example, exogenous application of CKs (benzyladenine) was shown to induce expression of phenylalanine ammonia-lyase, catalyzing the first step of isoflavones biosynthesis converting phenylalanine to cinnamic acid (Deikman and Hammer, 1995). Cytokinins may indirectly enhance the biosynthesis of isoflavones by boosting SA production which in turn induces the expression of isoflavone synthase (IFS), inovoled in the conversion of flavones (liquiritigenin) to daizein and genistein (Subramanian et al., 2004).

Plant growth hormones play a vital role in plant growth and development, and their responses to environmental changes are of significant importance in understanding acclimation mechanism of plants exposed to biotic and abiotic stresses. Recently it has been suggested those CKs: ABA ratios in xylem sap control stress signaling (Alvarez et al., 2008; Schachtman and Goodger, 2008). Salt stress represses the expression of isopentenyl transferase, a gene involved in the biosynthesis of CKs in ABA dependent and independent manner, thus reducing CKs content and its signaling (Nishiyama et al., 2011). Addition of Kn to the system recovered soybean seedlings from the damaging effects of salt stress by restoring CKs signaling which reduced ABA contents and delayed senescence (Figure 9). Contrary to its inhibitory action on ABA biosynthesis, application of exogenous $\mathrm{Kn}$ enhanced the contents of major phytohormones including SA, JA, and GAs among which the last two are inhibited by the application of $\mathrm{NaCl}$. Beside its effect on phytohormones, $\mathrm{Kn}$ antagonized $\mathrm{NaCl}$ by enhancing photosynthesis and avoiding senescence. In current study, the levels of bioactive GA1 and GA4 considerably increased with elevated $\mathrm{Kn}$, but declined under saline stress. An interactive application appears to rescue GA biosynthesis, as significantly higher levels of bioactive GAs were found in elevated $\mathrm{Kn}$ treated plants, as compared to sole $\mathrm{NaCl}$ applied plants. GA stimulates growth by promoting the destruction of DELLAs (Fu et al., 2004), while a decline in endogenous GA biosynthesis was due to the activation of growth-repressing effects of DELLAs, as salt-activated signaling pathways enhance DELLA production (Achard et al., 2006). Contrary to GA, accumulation of DELLAs prolongs the phase of vegetative growth and slows the overall rate of growth. This enhanced growth repression is distinct from passive growth rate reductions due to salt-induced perturbation of the physiological and metabolic processes that drive growth (Achard et al., 2006). In vegetative plant tissues, GA is mostly synthesized by an Early $\mathrm{C}_{13}$-hydroxylation pathway (Sponsel, 1987), though other pathways, especially the non-C13-hydroxylation pathways, are also often present (Zhu et al., 1991). Current findings showed the presence of both these pathways in soybean, and non- $\mathrm{C}_{13}$ hydroxylation that leads to the biosynthesis of $\mathrm{GA}_{4}$, is the major GA biosynthesis pathway in soybean.

In current study, contrary to bioactive GAs, endogenous contents of free ABA significantly enhanced in salt affected soybean but declined in plants treated with $\mathrm{Kn}$ alone. The endogenous ABA usually increases under drought, salinity, and cold stress (Chen and Gusta, 1983; Larosa et al., 1987; González et al., 2001). A decline in ABA level clearly suggests that addition of Kn mitigated the adverse effects of salt stress, probably by promoting plant growth and subsequently hindering build-up of DELLA proteins. ABA pathway is involved in plant responses to diverse abiotic and biotic inputs, and it is more likely that DELLA restraint provides a general mechanism for integration of plant growth responses to the environment. Unlike ABA, the JA contents increases with elevated $\mathrm{Kn}$, but decreases in response to combine application of $\mathrm{Kn}$ and salt stress. An increase in JA content may be correlated with plant growth, which was higher in treatments. This increase in JA level can be better explained in context of vegetative storage proteins (VSP) formation, as higher VSP accumulation may have taken place under the influence of elevated Kn application (Jang et al., 2008). We observed that endogenous JA contents were significantly higher in sole $\mathrm{NaCl}$ treated plants as compared to control, which shows that JA could be involved in the perception of stress factors. Current study confirms previous reports about JA involvement in the perception of stress factors (Pedranzani et al., 2003), and an increase in JA contents in response to salt stress (Wang et al., 


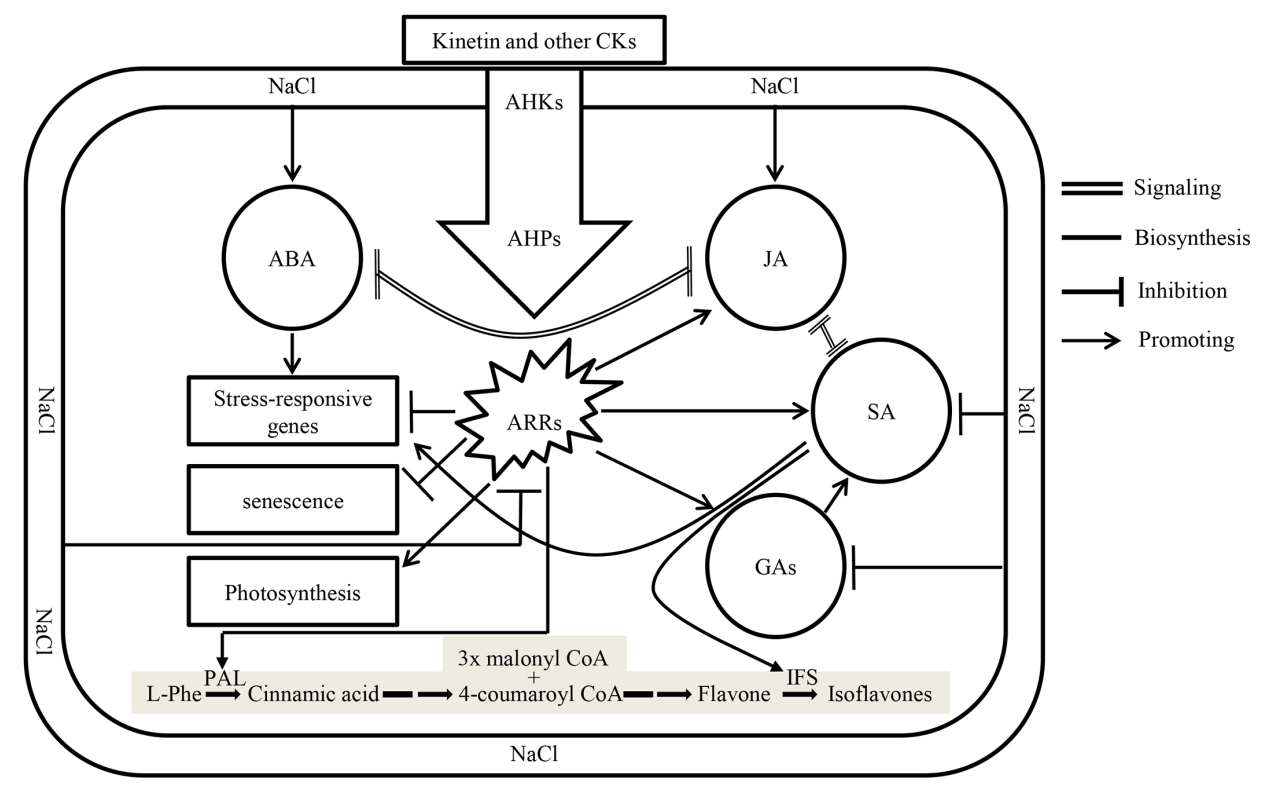

FIGURE 9 | A model showing crosstalk between different phytohormones under the influence of $\mathrm{NaCl}$ and exogenous $\mathbf{K n}$.

Application of salts enhances biosynthesis of ABA and JA which antagonize signaling of each other. Enhanced biosynthesis of ABA induces the expression of salt-responsive genes. Simultaneously, cytokinin (CKs) signaling, along with the biosynthesis of GAs and SA are antagonized in salt stressed plants. Application of $\mathrm{Kn}$ (a type of CKs) restores CKs signaling by activating transcription factors ARRs via its receptors in membrane, i.e., AHKs and downstream response regulators AHPs thereby delaying senescence, restoring photosynthesis and enhancing the biosynthesis of GAs, SA, and JA accompanied by decline in ABA concentration and signaling. The shaded pathway is indicating the biosynthesis of isoflavones in legumes, where the expression of two key enzymes, phenylalanine ammonia lyase (PAL) and isoflavone synthase (IFS) is induced by CKs and SA, respectively.
2001). Reduction in JA level under the combined influence of salt stress and Kn suggested that alleviation of salt stress by this CK is independent of JA signaling. However, in the absence exogenous CKs, JA signaling may be important for salt stress tolerance achieved by upregulating the expression of arginine decarboxylase, ribulose 1-5-bisphosphate carboxylase/oxygenase (Rubisco) activase and apoplastic invertase genes (Walia et al., 2007). Low JA phenotype of seedlings receiving both CKs and $\mathrm{NaCl}$ may be due to the enhanced production of SA which is known to inhibit JA signaling and therefore may indirectly reduce JA biosynthesis. High GAs in CKs treated seedlings may act synergistically with SA in reducing JA signaling thereby making plant insensitive to JA. Additionally, enhanced GAs also promote SA signaling by degrading DELLAs proteins (Navarro et al., 2008).

Salicylic acid is an important signaling substance that induces systemic acquired resistance (SAR) against pathogenic attack on plants (Siegrist et al., 2000). We observed that SA contents of soybean fractionally increased in Kn added treatments, while significantly up-regulated in plants that received both $\mathrm{Kn}$ and $\mathrm{NaCl}$. Taking this together with reduced in SA contents of seedlings grown under salt stress alone, a positive role of SA for salt stress tolerance in soybean is suggested. Previous reports on the role of SA for salt stress have been contradictory. It has been shown that SA increases the oxidative damage generated by $\mathrm{NaCl}$ stress via amplifying the effects of ROS initial levels, which in turn is critical for seedling lethality under salt stress. Using mutant Arabidopsis, a similar role in stress response and plant-pathogen interaction has been proposed for SA, claiming that SA signaling forms a feedback amplification cycle in concert with ROS (Jabs, 1999). However, low SA mutants are not tolerant to high amount of salt, indicating that part of the oxidative stress generated during $\mathrm{NaCl}$ exposure is independent of the SA (Borsani et al., 2001). Contrary to this, NPR1-dependent SA signaling plays central role for salt and oxidative stress tolerance in Arabidopsis (Jayakannan et al., 2015).

\section{Conclusion}

Kinetin triggers higher growth and isoflavones contents in soybean, and mitigated the adverse effects of $\mathrm{NaCl}$ induced salt stress. The favorable role of $\mathrm{Kn}$ in mitigating salt stress is evident from the levels of endogenous phytohormones, which provides an important clue for understanding the defense mechanisms of soybean against salinity. $\mathrm{NaCl}$ exerts adverse effect on plant growth by enhancing the production of growth inhibitory hormone ABA accompanied by a decline in the level of growth and defense related hormones including CKs, GAs, and SA. To counteract the salt stress, level of endogenous JA is enhanced which is involved in the perception of stress factors. The exogenous application of $\mathrm{Kn}$ oppose the effect of salt stress by reducing ABA level and promoting the production GAs and SA. Alleviation of salt stress by $\mathrm{Kn}$ is independent of JA 
signaling, indicated by the low level JA phenotype under the combined influence of salt and $\mathrm{Kn}$. Kn also enhances isoflavones biosynthesis directly by inducing the expression of key enzymes of the pathway or by SA signaling which together with growth regulation, augment food quality.

\section{References}

Achard, P., Cheng, H., De Grauwe, L., Decat, J., Schoutteten, H., Moritz, T., et al. (2006). Integration of plant responses to environmentally activated phytohormonal signals. Science 311, 91-94. doi: 10.1126/science.1 118642

Allred, C. D., Allred, K. F., Ju, Y. H., Goeppinger, T. S., Doerge, D. R., and Helferich, W. G. (2004). Soy processing influences growth of estrogen-dependent breast cancer tumors. Carcinogenesis 25, 1649-1657. doi: 10.1093/carcin/bgh178

Alvarez, S., Marsh, E. L., Schroeder, S. G., and Schachtman, D. P. (2008). Metabolomic and proteomic changes in the xylem sap of maize under drought. Plant Cell Environ. 31, 325-340. doi: 10.1111/j.1365-3040.2007.01770.x

Apse, M. P., Aharon, G. S., Snedden, W. A., and Blumwald, E. (1999). Salt tolerance conferred by overexpression of a vacuolar $\mathrm{Na}^{+} / \mathrm{H}^{+}$antiport in Arabidopsis. Science 285, 1256-1258. doi: 10.1126/science.285.5431.1256

Bartels, D., and Sunkar, R. (2005). Drought and salt tolerance in plants. Crit. Rev. Plant Sci. 24, 23-58. doi: 10.1080/07352680590910410

Barz, W., and Welle, R. (1992). "Biosynthesis and metabolism of isoflavones and pterocarpan phytoalexins in chickpea, soybean and phytopathogenic fungi," in Phenolic Metabolism in Plants, eds R. K. Ibrahim and H. A. Stafford (New York, NY: Springer), 139-164.

Bohm, W. (ed.). (1979). Methods of Studying Root Systems. Berlin: Springer-Verlag. doi: 10.1007/978-3-642-67282-8

Borsani, O., Valpuesta, V., and Botella, M. A. (2001). Evidence for a role of salicylic acid in the oxidative damage generated by $\mathrm{NaCl}$ and osmotic stress in Arabidopsis seedlings. Plant physiol. 126, 1024-1030. doi: 10.1104/pp.126.3.1024

Chakrabarti, N., and Mukherji, S. (2003). Alleviation of $\mathrm{NaCl}$ stress by pretreatment with phytohormones in Vigna radiata. Biol. Plantarum 46, 589594. doi: 10.1023/A:1024827931134

Chen, T. H. H., and Gusta, L. V. (1983). Abscisic acid-induced freezing resistance in cultured plant cells. Plant Physiol. 73, 71-75. doi: 10.1104/pp.73.1.71

Creelman, R. A., and Mulpuri, R. (2002). The oxylipin pathway in Areeeabidopsis. Arabidopsis Book Am. Soc. Plant Biol. 1:e0012. doi: 10.1199/tab.0012

Dangelmayr, B., Stotz, G., Spribille, R., and Forkmann, G. (1983). Relationship between flower development anthocyanin accumulation and activity of enzymes involved in flavonoid biosynthesis in Matthiola incana R. Br. $\mathrm{Z}$. Naturforsch. Biosci. 38, 551-555.

Deikman, J., and Hammer, P. E. (1995). Induction of anthocyanin accumulation by cytokinins in Arabidopsis thaliana. Plant Physiol. 108, 47-57.

Enyedi, A. J., Yalpani, N., Silverman, P., and Raskin, I. (1992). Localization, conjugation, and function of salicylic acid in tobacco during the hypersensitive reaction to tobacco mosaic virus. Proc. Natl. Acad. Sci. U.S.A. 89, 2480-2484. doi: 10.1073/pnas.89.6.2480

Fu, X., Richards, D. E., Fleck, B., Xie, D., Burton, N., and Harberd, N. P. (2004). The Arabidopsis mutant sleepylgar2-1 protein promotes plant growth by increasing the affinity of the SCFSLY1 E3 ubiquitin ligase for DELLA protein substrates. Plant Cell 16, 1406-1418. doi: 10.1105/tpc.021386

Gerats, A. G. M., Wallroth, M., Donker-Koopman, W., Groot, S. P. C., and Schram, A. W. (1983). The genetic control of the enzyme UDP-glucose: 3-0flavonoid-glucosyltransferase in flowers of Petunia hybrida. Theor. Appl. Genet. 65, 349-352. doi: 10.1007/BF00276576

González, E. M., Gálvez, L., and Arrese-Igor, C. (2001). Abscisic acid induces a decline in nitrogen fixation that involves leghaemoglobin, but is independent of sucrose synthase activity. J. Exp. Bot. 52, 285-293. doi: 10.1093/jexbot/52.355.285

Gunes, A., Inal, A., Alpaslan, M., Eraslan, F., Bagci, E. G., and Cicek, N. (2007). Salicylic acid induced changes on some physiological parameters symptomatic

\section{Acknowledgments}

This research was supported by Basic Science Research Program through the National Research Foundation of Korea (NRF), funded by the Ministry of Education (2014R1A1A2A10058022), Republic of Korea.

for oxidative stress and mineral nutrition in maize (Zea mays L.) grown under salinity. J. Plant Physiol. 164, 728-736. doi: 10.1016/j.jplph.2005.12.009

Hamayun, M., Khan, S. A., Khan, A. L., Shin, J.-H., Ahmad, B., Shin, D.-H., et al. (2010). Exogenous gibberellic acid reprograms soybean to higher growth and salt stress tolerance. J. Agric. Food Chem. 58, 7226-7232. doi: 10.1021/jf10 $1221 \mathrm{t}$

Hayat, Q., Hayat, S., Irfan, M., and Ahmad, A. (2010). Effect of exogenous salicylic acid under changing environment: a review. Environ. Exp. Bot. 68, 14-25. doi: 10.1016/j.envexpbot.2009.08.005

Hussain, T. M., Hazara, M., Sultan, Z., Saleh, B. K., and Gopal, G. R. (2008). Recent advances in salt stress biology a review. Biotechnol. Mol. Biol. Rev. 3, 8-13.

Jabs, T. (1999). Reactive oxygen intermediates as mediators of programmed cell death in plants and animals. Biochem. Pharmacol. 57, 231-245. doi: 10.1016/S0006-2952(98)00227-5

Jang, S. W., Hamayun, M., Sohn, E. Y., Shin, D. H., Kim, K. U., Lee, B. H., et al. (2008). Effect of elevated nitrogen levels on endogenous gibberellin and jasmonic acid contents of three rice (Oryza sativa L.) cultivars. J. Plant Nutr. Soil Sci. 171, 181-186. doi: 10.1002/jpln.200625025

Javid, M. G., Sorooshzadeh, A., Moradi, F., Modarres Sanavy, S. A. M., and Allahdadi, I. (2011). The role of phytohormones in alleviating salt stress in crop plants. Aust. J. Crop Sci. 5:726.

Jayakannan, M., Bose, J., Babourina, O., Shabala, S., Massart, A., Poschenrieder, C., et al. (2015). The NPR1-dependent salicylic acid signalling pathway is pivotal for enhanced salt and oxidative stress tolerance in Arabidopsis. J. Exp. Bot. 66, 1865-1875. doi: 10.1093/jxb/eru528

Kao, W. Y., Tsai, T. T., and Shih, C. N. (2003). Photosynthetic gas exchange and chlorophyll a fluorescence of three wild soybean species in response to $\mathrm{NaCl}$ treatments. Photosynthetica 41, 415-419. doi: 10.1023/B:PHOT.0000015466.22288.23

Keskin, B. C., Yuksel, B., Memon, A. R., and Topal-Sarikaya, A. (2010). Abscisic acid regulated gene expression in Bread Wheat ('Triticum aestivum' L.). Aust. J. Crop Sci. 4, 617-625.

Khan, N. A. (2003). NaCl-inhibited chlorophyll synthesis and associated changes in ethylene evolution and antioxidative enzyme activities in wheat. Biol. Plantarum 47, 437-440. doi: 10.1023/B:BIOP.0000023890.01126.43

Kirst, G. O. (1990). Salinity tolerance of eukaryotic marine algae. Annu. Rev. Plant Biol. 41, 21-53. doi: 10.1146/annurev.pp.41.060190.000321

Koch, T., Krumm, T., Jung, V., Engelberth, J., and Boland, W. (1999). Differential induction of plant volatile biosynthesis in the lima bean by early and late intermediates of the octadecanoid-signaling pathway. Plant Physiol. 121, 153162. doi: $10.1104 /$ pp.121.1.153

Larosa, P. C., Hasegawa, P. M., Rhodes, D., Clithero, J. M., Watad, A.-E. A., and Bressan, R. A. (1987). Abscisic acid stimulated osmotic adjustment and its involvement in adaptation of tobacco cells to NaCl. Plant Physiol. 85, 174-181. doi: $10.1104 /$ pp.85.1.174

Lee, I.-J., Foster, K. R., and Morgan, P. W. (1998). Photoperiod control of gibberellin levels and flowering in sorghum. Plant Physiol. 116, 1003-1011. doi: 10.1104/pp.116.3.1003

Magome, H., Yamaguchi, S., Hanada, A., Kamiya, Y., and Oda, K. (2004). dwarf and delayed-flowering 1, a novel Arabidopsis mutant deficient in gibberellin biosynthesis because of overexpression of a putative AP2 transcription factor. Plant J. 37, 720-729. doi: 10.1111/j.1365-313X.2003.01998.x

McCloud, E. S., and Baldwin, I. T. (1997). Herbivory and caterpillar regurgitants amplify the wound-induced increases in jasmonic acid but not nicotine in Nicotiana sylvestris. Planta 203, 430-435. doi: 10.1007/s004250050210

Messina, M. (2000). Soyfoods and soybean phyto-oestrogens (isoflavones) as possible alternatives to hormone replacement therapy (HRT). Eur. J. Cancer 36, 71-72. doi: 10.1016/S0959-8049(00)00233-1 
Misra, N., and Gupta, A. K. (2005). Effect of salt stress on proline metabolism in two high yielding genotypes of green gram. Plant Sci. 169, 331-339. doi: 10.1016/j.plantsci.2005.02.013

Munns, R., James, R. A., and Läuchli, A. (2006). Approaches to increasing the salt tolerance of wheat and other cereals. J. Exp. Bot. 57, 1025-1043. doi: 10.1093/jxb/erj100

Navarro, L., Bari, R., Achard, P., Lisãn, P. N., Nemri, A., Harberd, N. P., et al. (2008). DELLAs control plant immune responses by modulating the balance of jasmonic acid and salicylic acid signaling. Curr. Biol. 18, 650-655. doi: 10.1016/j.cub.2008.03.060

Nemat Alla, M. M., Younis, M. E., El-Shihaby, O. A., and El-Bastawisy, Z. M. (2002). Kinetin regulation of growth and secondary metabolism in waterlogging and salinity treated Vigna sinensis and Zea mays. Acta Physiol. Plantarum 24, 19-27. doi: 10.1007/s11738-002-0017-5

Nishiyama, R., Watanabe, Y., Fujita, Y., Le, D. T., Kojima, M., Werner, T. S., et al. (2011). Analysis of cytokinin mutants and regulation of cytokinin metabolic genes reveals important regulatory roles of cytokinins in drought, salt and abscisic acid responses, and abscisic acid biosynthesis. Plant Cell 23, 2169-2183. doi: 10.1105/tpc.111.087395

Norlyn, J. D., and Epstein, E. (1984). Variability in salt tolerance of four triticale lines at germination and emergence. Crop Sci. 24, 1090-1092. doi: 10.2135/cropsci1984.0011183X002400060019x

Omoni, A. O., and Aluko, R. E. (2005). Soybean foods and their benefits: potential mechanisms of action. Nutr. Rev. 63, 272-283. doi: 10.1111/j.17534887.2005.tb00141.x

Ososki, A. L., and Kennelly, E. J. (2003). Phytoestrogens: a review of the present state of research. Phytother. Res. 17, 845-869. doi: 10.1002/ptr.1364

Pathan, M. S., Lee, J.-D., Shannon, J. G., and Nguyen, H. T. (2007). "Recent advances in breeding for drought and salt stress tolerance in soybean," in Advances in Molecular Breeding Toward Drought and Salt Tolerant Crops, eds M. A. Jenks, P. M. Hasegawa, and S. M. Jain (Houten: Springer), 739-773. doi: 10.1007/978-1-4020-5578-2_30

Pedranzani, H., Racagni, G., Alemano, S., Miersch, O., Ramírez, I., PeñaCortés, H., et al. (2003). Salt tolerant tomato plants show increased levels of jasmonic acid. Plant Growth Regul. 41, 149-158. doi: 10.1023/A:10273113 19940

Phommalth, S., Jeong, Y.-S., Kim, Y.-H., Dhakal, K. H., and Hwang, Y.-H. (2008). Effects of light treatment on isoflavone content of germinated soybean seeds J. Agric. Food Chem. 56, 10123-10128. doi: 10.1021/jf802118g

Rostagno, M. A., Palma, M., and Barroso, C. G. (2003). Ultrasound-assisted extraction of soy isoflavones. J. Chromatogr. A 1012, 119-128. doi: 10.1016/S0021-9673(03)01184-1

Schachtman, D. P., and Goodger, J. Q. (2008). Chemical root to shoot signaling under drought. Trends Plant Sci. 13, 281-287. doi: 10.1016/j.tplants.2008.04.003

Seskar, M., Shulaev, V., and Raskin, I. (1998). Endogenous methyl salicylate in pathogen-inoculated tobacco plants. Plant Physiol. 116, 387-392. doi: 10.1104/pp.116.1.387

Sharma, R. R., and Singh, R. (2009). Gibberellic acid influences the production of malformed and button berries, and fruit yield and quality in strawberry (Fragaria ananassa Duch.). Sci. Horticult. 119, 430-433. doi: 10.1016/j.scienta.2008.11.002

Siegrist, J., Orober, M., and Buchenauer, H. (2000). $\beta$-Aminobutyric acid-mediated enhancement of resistance in tobacco to tobacco mosaic virus depends on the accumulation of salicylic acid. Physiol. Mol. Plant Pathol. 56, 95-106. doi: 10.1006/pmpp.1999.0255

Singh, S., and Jain, S. (1982). Effect of some growth regulators on certain biochemical parameters during seed development in chickpea under salinity. Indian J. Plant Physiol. 20, 167-179.
Sponsel, V. M. (1987). "Gibberellin biosynthesis and metabolism," in Plant Hormones and Their Role in Plant Growth and Development, ed. D. Peter (Dordrecht: Springer), 43-75. doi: 10.1007/978-94-009-3585-3_4

Subramanian, S., Hu, X., Lu, G., Odelland, J. T., and Yu, O. (2004). The promoters of two isoflavone synthase genes respond differentially to nodulation and defense signals in transgenic soybean roots. Plant Mol. Biol. 54, 623-639. doi: 10.1023/B:PLAN.0000040814.28507.35

Tester, M., and Davenport, R. (2003). $\mathrm{Na}^{+}$tolerance and $\mathrm{Na}^{+}$transport in higher plants. Ann. Bot. 91, 503-527. doi: 10.1093/aob/mcg058

Thomas, J. C., and Bohnert, H. J. (1993). Salt stress perception and plant growth regulators in the halophyte Mesembryanthemum crystallinum. Plant Physiol. 103, 1299-1304.

Tran, L.-S. P., Urao, T., Qin, F., Maruyama, K., Kakimoto, T., Shinozaki, K., et al. (2007). Functional analysis of AHK1/ATHK1 and cytokinin receptor histidine kinases in response to abscisic acid, drought, and salt stress in Arabidopsis. Proc. Natl. Acad. Sci. U.S.A. 104, 20623-20628. doi: 10.1073/pnas.0706 547105

Verbruggen, N., and Hermans, C. (2008). Proline accumulation in plants: a review. Amino acids 35, 753-759. doi: 10.1007/s00726-008-0061-6

Walia, H., Wilson, C., Condamine, P., Liu, X., Ismail, A. M., and Close, T. J. (2007). Large-scale expression profiling and physiological characterization of jasmonic acid-mediated adaptation of barley to salinity stress. Plant Cell Environ. 30, 410-421. doi: 10.1111/j.1365-3040.2006.01628.x

Wang, X.-Q., Ullah, H., Jones, A. M., and Assmann, S. M. (2001). G protein regulation of ion channels and abscisic acid signaling in Arabidopsis guard cells. Science 292, 2070-2072. doi: 10.1126/science.1059046

Wasternack, C., and Hause, B. (2002). Jasmonates and octadecanoids: signals in plant stress responses and development. Prog. Nucleic Acid Res. Mol. Biol. 72, 165-221. doi: 10.1016/S0079-6603(02)72070-9

Wasternack, C., and Parthier, B. (1997). Jasmonate-signalled plant gene expression. Trends Plant Sci. 2, 302-307. doi: 10.1016/S1360-1385(97)89952-9

Winkel-Shirley, B. (2001). Flavonoid biosynthesis. A colorful model for genetics, biochemistry, cell biology, and biotechnology. Plant Physiol. 126, 485-493. doi: 10.1104/pp.126.2.485

Yoon, J. Y., Hamayun, M., Lee, S.-K., and Lee, I.-J. (2009). Methyl jasmonate alleviated salinity stress in soybean. J. Crop Sci. Biotechnol. 12, 63-68. doi: 10.1007/s12892-009-0060-5

Zhu, J.-K. (2002). Salt and drought stress signal transduction in plants. Annu. Rev. Plant Biol. 53, 247-273. doi: 10.1146/annurev.arplant.53.091401. 143329

Zhu, J.-K., Liu, J., and Xiong, L. (1998). Genetic analysis of salt tolerance in Arabidopsis: evidence for a critical role of potassium nutrition. Plant Cell 10, 1181-1191. doi: 10.1105/tpc.10.7.1181

Zhu, Y.-X., Davies, P. J., and Halinska, A. (1991). Metabolism of Gibberellin A12 and A12-Aldehyde in Developing Seeds of Pisum sativum L. Plant Physiol. 97, 26-33. doi: 10.1104/pp.97.1.26

Conflict of Interest Statement: The authors declare that the research was conducted in the absence of any commercial or financial relationships that could be construed as a potential conflict of interest.

Copyright (c) 2015 Hamayun, Hussain, Khan, Irshad, Khan, Waqas, Shahzad, Iqbal, Ullah, Rehman, Kim and Lee. This is an open-access article distributed under the terms of the Creative Commons Attribution License (CC BY). The use, distribution or reproduction in other forums is permitted, provided the original author(s) or licensor are credited and that the original publication in this journal is cited, in accordance with accepted academic practice. No use, distribution or reproduction is permitted which does not comply with these terms. 